\title{
EXPERIMENTAL HEMERALOPIA UNCOMPLICATED BY XEROPHTHALMIA IN MACACUS RHESUS*
}

BY

\author{
F. C. RODGER †, A. D. GROVER, AND A. FAZAL \\ From the Institute of Ophthalmology, Aligarh University, India
}

THE primary aim of this study was to see whether structural changes occurred in the retinae of monkeys suffering from night blindness as a result of a deficiency of vitamin A induced in such a way that xerophthalmia would not complicate matters. In India, as elsewhere, night blindness is common as an isolated phenomenon for which there may be several causes in addition to that of vitamin A deficiency (Rodger, Dhir, and Hosain, 1960). It has even been reported as an endemic disease (Patwardhan, 1958). The studies of Wald, Jeghers, and Arminio (1938), Wald, Brouha, and Johnson (1942), and Hume and Krebs (1949) have shown without question that a raised light threshold can be induced in human subjects placed on a diet deficient in vitamin A without the complication of xerosis of the cornea; the reason for this seems to depend on the rapidity with which the vitamin A status is lowered in man to a critical level below which symptoms of night blindness develop, and this in turn seems to depend upon the state of the liver reserve of vitamin A at the outset of the deficiency. Such studies as those just mentioned and that of Tilden and Miller (1930) on monkeys, not to speak of our own experience of avitaminosis A in the tropics, strongly suggested that the way to achieve the aim of inducing hemeralopia, without xerophthalmia complicating the response to light and the histology, is to ensure that there is a good liver reserve of vitamin A at the outset, even although it is likely to prolong the study somewhat.

From the work of Tansley (1933), Johnson (1939, 1943), Ramalingaswami, Leach, and Sriramachari (1955), and Dowling and Wald (1958), it is clear that gross retinal degeneration occurs in rats and monkeys at a stage of deficiency at which the corneal epithelium and stroma are both involved; such retinal changes, of course, need not necessarily exist when the external eye is healthy and the sole complaint that of night blindness. We have in fact no idea of the appearance of the retina in such circumstances, either in man (where the eye cannot be removed) or in experimental animals (for these conditions have never been reproduced). Where xerophthalmia is present in man, the plasma values of the vitamin and of carotenoids, are low, more

* Received for publication April 29, 1960.

† Present appointment: Consultant Ophthalmic Surgeon, Princess Margaret Hospital, Swindon, Wilts. 
especially the former, and as far as one knows the liver reserves are nearing depletion, if not already depleted. Clearly severe night blindness must exist. On the other hand where night blindness is an early symptom, it is generally agreed that the plasma values of vitamin A may be reduced only moderately, if at all, although the carotenoid values may be halved (Hume and Krebs, 1949). As the deficiency persists, however, there is no doubt the vitamin A levels are reduced relatively more than the carotenoid (Rodger, Saiduzzafar, Grover, and Fazal, unpublished). One is forced to assume from this that there is a critical blood level (which varies for the individual) at which hemeralopia develops in man before xerosis appears.

Dowling and Wald (1958) claim to have produced evidence (in the rat), by using the electroretinogram, that night blindness existed before the animals were killed. Unfortunately, xerosis of the cornea was present, and moreover the histological work is not very convincingly reported in this paper. Changes in the rat retina are difficult to interpret because it is subject to spontaneous degenerations, often found in control animals, and in addition it is especially prone to artefact. All these factors influenced the format of the present study: we selected monkeys in preference to rats; we used a dark adaptometer specially devised to replace the electroretinogram in the hope that it would provide substantial direct evidence that the thresholds were raised; we planned the experiment with the intention of producing hemeralopia but not xerophthalmia; when we examined the retinae we used the low viscosity nitrocellulose method of embedding which gives rise to the minimum of distortion (Leach, 1952).

\section{Methods}

(1) Selection of Animals.-Ten healthy young growing Macacus rhesus monkeys averaging about $5 \mathrm{lb}$. in weight at the outset were selected from an initial stock of thirty obtained from a central laboratory. Seven were placed on a diet deficient in vitamin A, and three acted as controls, being fed throughout the stock animal-house diet for monkeys. Tuberculosis is a hazard among monkeys and one of the deficient animals died of this after a month. Three more died near the end of the study from an ulcerative colitis, which Tilden and Miller (1930) believe to be a true complication of avitaminosis A in Macacus rhesus; this lesion responds only to restitution of vitamin $A$ in the diet, antibiotics being ineffective. The results were based on the three animals which survived in good health until they were killed.

(2) Administration and Composition of Diet

(a) Solids (g.):

$\begin{array}{lllr}\text { Casein, vitamin free } & \ldots & \ldots & 22 \\ \text { Rice, roughly polished } & \ldots & \ldots & 75 \\ \text { Salt mixture, Steenbock } & 40 & \ldots & 4 \\ \text { Arachis oil, vitamin free } & \ldots & 4\end{array}$


FIG. 1 (a).-Dark-adaptation tunnel. Lightadapted monkey is on the point of entering the dark-adaptation chamber. Its subsequent passage down the tunnel, during which it will be required to circumvent four obstructing walls, is recorded by the system of lights on the central control panel.

Fig. 1 (b).-Diagram of electric wiring of darkadaptation tunnel, showing transformer to 5 volts, obstructions wired to neon lamps, roof lights, and pilot trigger at exit which indicates completion of journey.

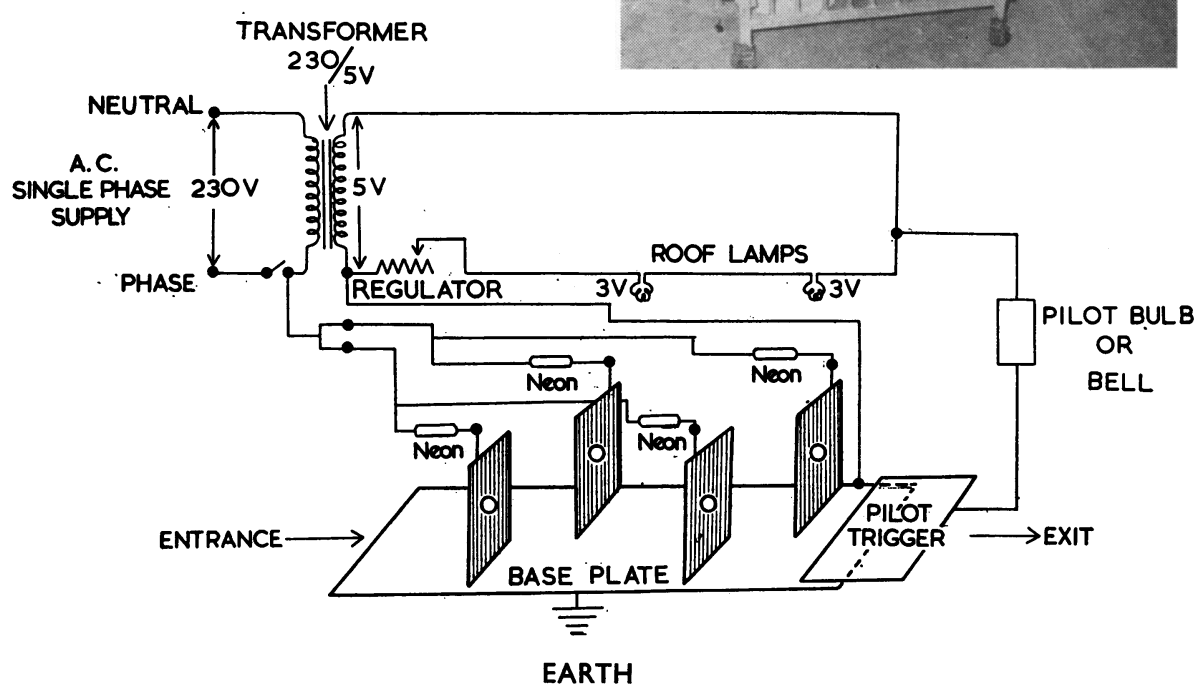

obstructing baffles at the end of 7 minutes; we have no reason to believe the monkeys reacted differently. Thus we hoped to investigate the curve around the point $\alpha$. The statistical analysis of the daily traverse times and touches was carried out from the figures available over a period of 7 months; the initial period of about a month when the animals were being taught to avoid the obstructions was ignored, and timings and touch counts were recorded subsequently during the 2-month period when vitamin A supplement was administered followed by a 5-month period when the monkeys were placed on a diet deficient in all but a trace of vitamin A (present in half a banana). 
(4) Other ObSERVATIONS.-The animals were weighed every fortnight. The eyes were examined with the hand slit lamp and the loupe at weekly intervals, and even more frequently towards the end. Blood samples for estimating the vitamin $A$ and carotenoid values were taken at the start-before giving the vitamin A supplement-and at the finish. The values were not very high at the outset and it seems probable that the diet given in the central laboratory from which the animals came had not been rich in vitamin A. The eyeballs were enucleated under an anaesthetic immediately before death, which was induced by superimposing a lethal dose of Nembutal on the surgical dose. Liver slices were examined with the fluorescent microscope.

(5) Histological TechniQue.-The eyes were fixed briefly in Bouin's solution and blocked in low viscosity nitrocellulose, and the sections were stained with Masson, Mallory, van Gieson, Weigert's elastic tissue stain, and periodic acidSchiff. Unstained sections were also mounted at the outset so that any subsequent bleaching of the pigment might be assessed. It is important to note that when sections are left for some months in alcohol in light, the residual picric acid from the fixative tends to bleach the pigment, a process expedited by the Mallory phosphotungstic acid technique, especially where the latter stain is oxidized by potassium permanganate instead of being left to ripen on its own.

\section{Results}

(1) GROwTH.-Fig. 2(opposite) gives the growth curves of the three deficient monkeys, the rations of which contained only a very slight trace of vitamin A. It can be seen that within 10 to 20 weeks of starting the deficient diet the weights started to fall. The curves are parallel. After 5 months on the diet each of the monkeys weighed less than at the outset 7 months before, whereas the three control monkeys had doubled their weights. Despite this, the three deficient animals remained remarkably active throughout the experiment up to the start of the 5th month on the deficient diet. As soon as the three showed signs of hemeralopia, they were killed. Right up to the end the external membranes of the eyes remained unaffected; there was no xerophthalmia.

(2) THRESHOLD FOR Light

(a) Traverse Times (Table I, opposite).-An analysis of variance showed that only deficient Monkey 1 exhibited a significant alteration in the time taken to pass through the tunnel, his daily traverse time increasing over 33 weeks by about 5 seconds. On this evidence only one monkey was night blind, but so slight were the differences throughout that there might be another explanation. In the three animals, the traverse time was roughly a foot a second all through, which means that they consistently from the start moved carefully in the dark; only Monkey 1 slowed down in the last month. A fair criticism might be made, if it were not for these figures, that as the days passed the monkeys became careless, a fact which would 


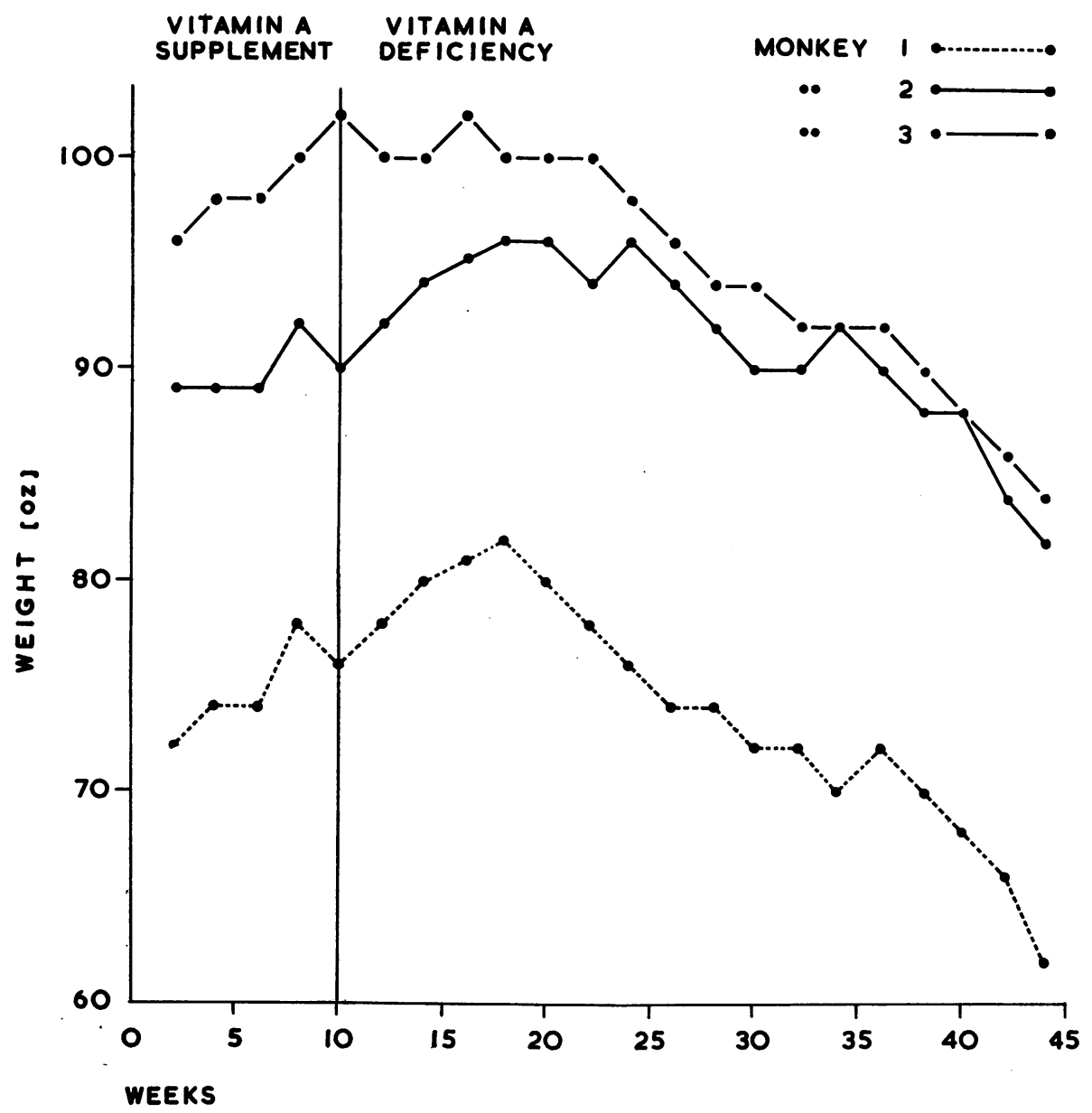

Fig. 2.-Growth curves of three Macacus rhesus monkeys over 35 weeks on a diet deficient in vitamin A.

TABLE I

MONTHLY MEAN DAILY TRAVERSE TIME (SEC.) WITHIN THE DARK-ADAPTATION TUNNEL

\begin{tabular}{|c|c|c|c|c|}
\hline \multirow{2}{*}{ Diet } & \multirow{2}{*}{ Month } & \multicolumn{3}{|c|}{ Monkey No. } \\
\hline & & 1 & 2 & 3 \\
\hline Normal & $\begin{array}{l}1 \\
2\end{array}$ & $\begin{array}{l}16 \cdot 7 \\
15 \cdot 6\end{array}$ & $\begin{array}{l}8 \cdot 9 \\
8 \cdot 2\end{array}$ & $\begin{array}{l}12 \cdot 6 \\
12 \cdot 0\end{array}$ \\
\hline Deficient & $\begin{array}{l}3 \\
4 \\
5 \\
6 \\
7\end{array}$ & $\begin{array}{l}16 \cdot 5 \\
15 \cdot 6 \\
16 \cdot 3 \\
18 \cdot 8 \\
21 \cdot 4\end{array}$ & $\begin{array}{r}9.0 \\
8.1 \\
9.0 \\
9.0 \\
11.0\end{array}$ & $\begin{array}{l}12 \cdot 8 \\
13 \cdot 1 \\
10 \cdot 0 \\
10 \cdot 2 \\
11 \cdot 7\end{array}$ \\
\hline
\end{tabular}


reveal itself by shorter traverse times; this did not occur. We feel, in the light of this, that any change shown to be significant statistically is likely to be a true change and not an illusory one caused by a variant resulting from animal behaviour, especially as all three monkeys maintained a good appetite throughout, and by their eager reactions showed clearly that they knew the significance of their trip through the tunnel.

(b) Touches (Table II).-Analysis of variance of the number of times the animals touched the obstructions showed a significant difference in all three monkeys as early as the 3rd month (at a time when the growth curves were falling sharply); at this point they were touching two, not one, of the obstructions as they had at the start; by the end of the 5th month on the other hand they quite frequently bumped into three if not all four of the obstructions. As their pace either remained the same or was slower, and the animals were quite steady and strong, this increased number of touches almost certainly represents a true increase, i.e. the touches were made by mistake because the monkeys no longer saw clearly at these low illuminations. Thus the dark adaptometer would seem to have fulfilled its purpose adequately.

TABLE II

MONTHLY MEAN DAILY TOUCHES ON OBSTRUCTING WALLS OF TUNNEL

\begin{tabular}{c|c|c|c|c}
\hline \multirow{2}{*}{ Diet } & \multirow{3}{*}{ Month } & \multicolumn{3}{|c}{ Monkey No. } \\
\cline { 2 - 4 } & & 1 & 2 & 3 \\
\hline \multirow{2}{*}{ Normal } & 1 & 1.15 & 0.81 & 1.67 \\
& 2 & 1.48 & 1.33 & 0.61 \\
\hline \multirow{3}{*}{ Deficient } & 3 & 1.32 & 1.47 & 1.10 \\
& 4 & 1.16 & 1.50 & 0.95 \\
& 5 & 1.92 & 2.13 & 1.75 \\
& 6 & 1.92 & 2.50 & 2.10 \\
& 7 & 2.85 & 2.65 & 2.70 \\
\hline
\end{tabular}

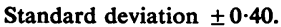

Standard error of the differences between 2 means \pm 0.28 .

Difference between means of four of 5 per cent. significance \pm 0.57 .

(3) Blood Values.-In all three animals fluorescence of the liver slices on termination of the experiment revealed that this organ had become almost if not completely depleted of vitamin A. When this observation is combined with the fact that the mean plasma vitamin A level for the group had fallen from 110.5 to $0 \cdot 10$ i.u. per $100 \mathrm{ml}$., and the mean carotenoid level from 75 to $44 \mathrm{mcg}$. per $100 \mathrm{ml}$., there can be little doubt that the animals were suffering from a marked degree of hemeralopia, especially if the subjective observations made with the dark adaptometer are also taken into consideration. 
(4) Microscopic ApPearance OF THE Eyes (Figs 3-6).-In all three control monkey eyes, for about $5 \mathrm{~mm}$. on each side of the fovea, the retinal pigment epithelium has a characteristic appearance, exactly corresponding to what we observe in the human eye. This appearance is one where the base of the epithelium is clear of all pigment, so that the round clear nucleus can be seen in each pigment cell. Pigment granules are present in the inner part of the cytoplasm of the pigment cell and in their processes. Outside this central (or posterior) area of the monkey fundus, the pigment distribution within the epithelium is more variable, tending always to be more dense, and to trespass on the outer (i.e. lower) part of the pigment cell, partly concealing the nucleus. The further out one goes (i.e. anteriorly), the greater is this effect.

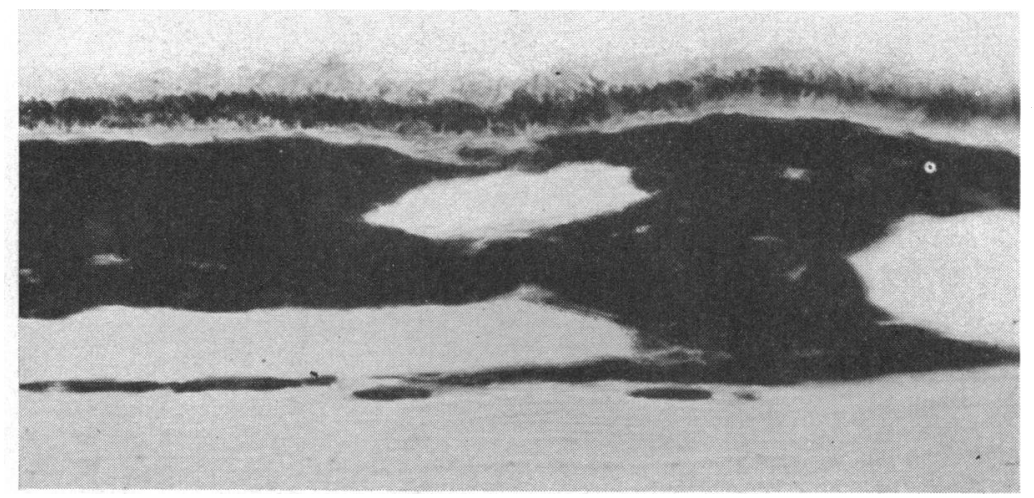

FIG. 3.-Retina of control monkey unstained. The faint line above the heavily pigmented choroid corresponds to the base of the retinal pigment epithelium. The clear space between this and the pigment granules above is characteristic of the cells in the posterior retina. $\times 500$.

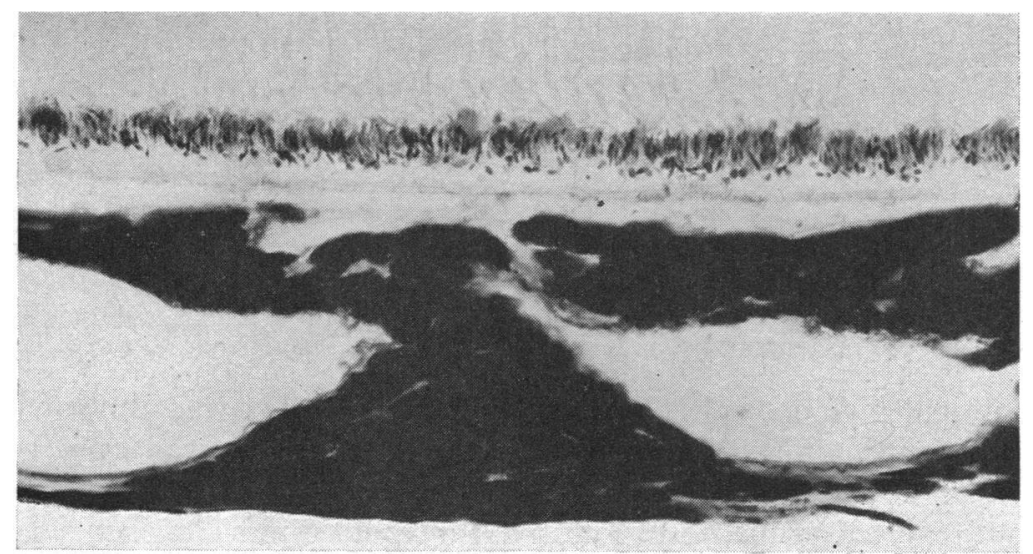

Fig. 4.- Retina of Monkey 7, deficient in vitamin A, unstained. Here the space between the base of the cell and the pigment granules has almost disappeared. $\times 500$. 


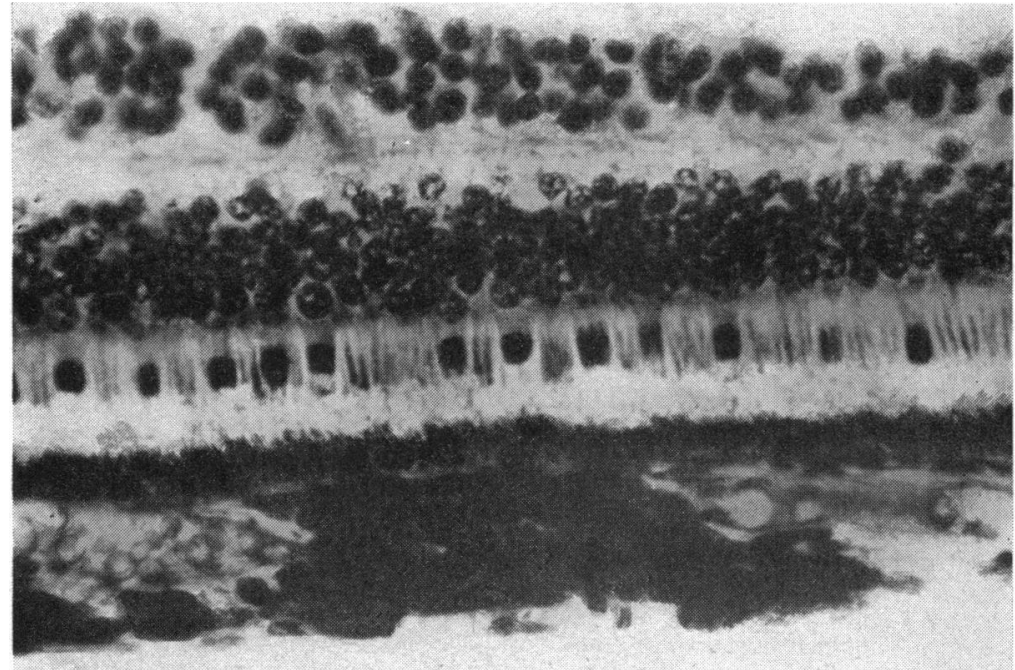

FIG. 5.-Retina of control monkey stained with Masson's trichrome technique. The nuclei of the retinal pigment epithelial cells are free of pigment. $\times 500$.

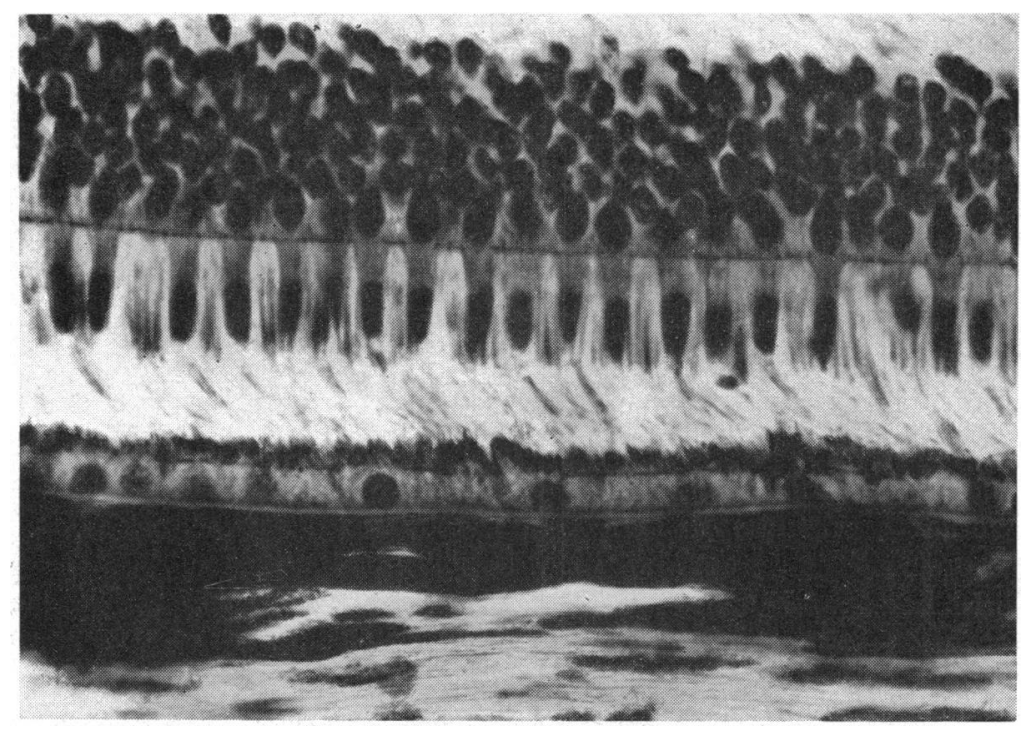

FIG. 6.-Retina of Monkey 6, deficient in vitamin A, stained with Masson's trichrome technique. Here the nuclei can no longer be seen. This is the only consistent change observed. $\times 500$.

The retinal pigment epithelium in the posterior area was abnormal in all three deficient monkeys. In one monkey the change was only partially significant; however, in a most striking manner the other two deficient monkeys revealed in the posterior area, for about $5 \mathrm{~mm}$. on each side of the fovea, a clumping of the pigment granules within the cell bodies of the pigment epithelium, so that the processes were somewhat denuded of 
pigment and the cell nuclei were concealed. The granules were less elliptical and rather less regular in distribution. This change is basically similar to that recorded by Ramalingaswami and others (1955). It was, however, the only change we discovered. There was no involvement of the rods and cones, of the ganglion cells, of the chorio-capillaris, or of any other cell or structure in the deficient retinae; nor did the anterior segments reveal any change indicative of xerophthalmia. In this respect the results of the present study differ from the others we have quoted.

\section{Discussion}

We shall assume that the premises, by which we concluded that the three deficient monkeys were night blind, are acceptable. The facts have been presented in full, and there seems no point in defending the procedures adopted. We shall, then, concentrate only on the results, and the most important of these are the structural changes in the retina. These changes we found to be slight, so slight that there must be doubt in some minds as to whether any existed at all. We believe that they did exist because they reflected the grosser changes described in similar studies by other workers. One should emphasize that in these other studies the liver reserves were not directly augmented at the start, and that the deficiency state was more rapidly attained and was more severe in degree than in our study; so severe were the changes obtained by these other workers that xerosis of the cornea, and even keratomalacia with rupture of the cornea, developed in the animals before they were killed.

Tansley (1933) was the first to seek changes of this nature. She utilized rats and dogs, the result in each case being essentially similar. Full details of the type and course of the deficiency states are unfortunately not given in her paper. By far the most definite of the changes she found was an absence of the yellow colour from the outer limbs of the rods when stained with potassium chloride, indicating an absence of visual purple. This is to be expected when the blood values of vitamin A are low. Structural changes, she says, were indefinite; they included the loss of the outer segments of the rods and cones here and there and the absence of differential staining between the inner and outer parts of the receptors not present in the control retinae. We did not find this. Tansley makes no mention of the pigment epithelium.

Johnson $(1939,1943)$, in a comprehensive study on 23-day weanling rats in which he used control animals (but not pair-fed), found no structural changes in the retinae in acute avitaminosis A, although the rats exhibited both xerophthalmia and keratomalacia. When the mothers were given a 10-day supplement of vitamin A before the weanling 23-day rats were placed on a vitamin A-free diet, however, the process of deficiency was slowed up; xerophthalmia was less destructive but the retinal changes were now gross. The changes included destruction of the rod and cone outer 
limbs and degeneration of the retinal pigment epithelium; movement of pigment granules could not be followed as albino rats apparently were used; at any rate such changes were not mentioned. There is no essential difference between Johnson's experimental criteria and results and those observed by Dowling and Wald (1958) in rats suffering from a similarly severe degree of deficiency.

Ramalingaswami and others (1955) have written up the structural changes at great length and have produced some beautiful pictures of the effect of a severe deficiency on the monkey eye. The species they used was Macacus sinicus, and we understand that these were wild monkeys (not laboratory bred), which were kept for several months in the laboratory before being used. The chief changes observed by these workers were that the retinal pigment epithelium exhibited structural alterations identical with those described in the present paper, and that there was also unequivocal evidence that the rod and cone cells were severely damaged. The dark-adaption test used in these experiments cannot, however, be considered satisfactory, and moreover the presence of corneal keratinization (as in the study by Dowling and Wald) must cast some doubt on the value of the methods adopted in each to ascertain whether the threshold had been altered, for any kind of corneal epithelial or stromal change would undoubtedly raise the threshold value. There is something equally unsatisfactory in the argument that because there was destruction of the rods and cones the animals must have suffered from hemeralopia. In the studies of Wald and his various collaborators, where human subjects were used, the threshold estimations revealing a rise were completely reliable; but the retinal picture naturally remained unknown. As explained in the Introduction, this is the lesion we hoped to investigate in monkeys.

We believe the evidence in the present study is very strong that our monkeys were no longer able to see in the low illumination which existed in the tunnel and that this must have been due to retinal dysfunction, because the optical media were clear. If that is so, it would seem that we reproduced in the Macacus rhesus study the exact circumstances surrounding the human experiments carried out by Wald and others $(1938,1942)$ and by Hume and Krebs (1949). Our results show that the structural changes underlying a hemeralopia of this type are essentially located in the retinal pigment epithelium. That is not to say, however, that there are no chemical, involving functional, changes in the rods and cones; with blood levels so low they probably co-exist. Such changes, as well as those affecting the pigment epithelium, are likely to be readily reversible when vitamin A is once again made available. Dowling and Wald (1958) suggested that, in prolonged deficiency of vitamin A, opsin became unstable and that this was an essential stage in the development of the severe damage to rods and cones which they described. "When this stage is reached", they write, "restoration of the normal threshold may prove impossible or long delayed." We cannot 
believe that this occurs apart from xerophthalmia. Damage of this nature is never likely to be made good, and where recovery of normal structure does not occur the damage would almost certainly be visible to the clinician, for these lesions are likely to result in pigmentary disturbance, gliosis, and infiltration; yet this has never been reported. Mention might be made in this connexion, however, of the suggestion put forward by Roger (1958) that the posterior degenerative lesion of onchocerciasis (where there is gross degeneration of this type in a limited posterior area) may be caused in part by avitaminosis $\mathrm{A}$, inasmuch as some degree of recovery of function is obtained with massive vitamin A therapy in early cases, especially the recovery of night vision, which is always affected. Roger emphasizes the fact, nevertheless, that the visible degenerative lesion was not found in those who suffered from avitaminosis $\mathrm{A}$ alone, but only in cases in which avitaminosis $\mathrm{A}$ was combined with onchocerciasis. He pointed out that the latter disease must surely be involved in some way. He exercised great caution in his account of what he believed the pathogenesis to be, but it is important to note that the ophthalmoscopic changes described first involved the retinal pigment epithelium at the posterior pole. In the light of the experimental evidence discussed here, this may be highly significant; however, it has yet to be shown that the great destruction of rods and cones typical of the advanced posterior degenerative lesion of onchocerciasis could occur as a result of avitaminosis A alone in the absence of some residual damage to the cornea, of which there is no sign.

The common factor in all these studies of the effect on the retina of avitaminosis $\mathrm{A}$ is that there is an anomaly of the retinal pigment epithelium. When the cornea is not involved, as shown here, this change is not one of localized dispersal or aggregation of pigment granules, but rather of their re-orientation within the epithelium. For that reason the absence of ophthalmoscopic evidence of structural changes in a simple uncomplicated hemeralopia is not surprising. On the other hand, because less light can reach and illuminate the choroid in such circumstances, the fundi would tend to be darker. It might well be that a close and detailed study would reveal a relationship between very dark fundi and vitamin A deficiency.

\section{Summary}

(1) Three monkeys (Macacus rhesus), placed on a vitamin A deficient diet after an initial supplement of the vitamin had been given to bolster the liver reserves, were shown to be night blind by means of a dark adaptometer especially designed for the purpose. The corneae were not involved.

(2) The fluorescent microscope revealed an absence of vitamin A from the liver and the blood levels were practically zero. 
(3) All three showed a re-orientation of the pigment in the retinal pigment epithelium, the pigment granules withdrawing into the cell bodies and concealing the nuclei.

The authors are grateful to Dr. F. H. C. Marriott for guidance in making the statistical analyses.

\section{REFERENCES}

Dowling, J. E., and Wald, G. (1958). Ann. N.Y. Acad. Sci., 74, 256.

Hume, E. M., and Krebs, H. A. (1949). Spec. Rep. Ser. med. Res. Counc. Lond., No. 264.

JoHNSON, M. L. (1939). J. exp. Zool., 81, 67.

(1943). Arch. Ophthal. (Chicago), 29, 793.

LEACH, E. H. (1952). Brit. J. Derm., 64, 183.

Patwardhan, V. N. (1958). Fed. Proc., 17, Suppl. 2, 110.

Ramalingaswami, V., Leach., E. H., and Sriramachari, S. (1955). Quart. J. exp. Physiol., 40, 337.

RODGER, F. C. (1958). Brit. J. Ophthal., 42, 21.

(1959). J. Physiol. (Lond.), 146, 27P.

DhIR, P. K., and Hosain, A. T. M. M. (1960). A.M.A. Arch. Ophthal., 63, 927.

, Saiduzzafar, H. S., Grover, A. D., and Fazal, A. (1959). Unpublished.

TANSLEY, K. (1933). Proc. roy. Soc. B., 114, 79.

Tilden, E. B., and Miller, E. G., Jr. (1930). J. Nutr., 3, 121.

Wald, G., Brouha, L., and Johnson, R. E. (1942). Amer. J. Physiol., 137, 551. , JeGHers, H., and ARMINIO, J. (1938). Ibid., 123, 732. 
Brit. J. Ophthal. (1961) 45, 384.

\section{BOOK REVIEW}

The Transparency of the Cornea. A Symposium (C.I.O.M.S.). Edited by STEWART Duke-Elder and E. S. Perkins. 1960. Pp. xii + 268, 67 figs. Blackwell Scientific Publications, Oxford. (45s.)

One of the most important, intriguing and, so far, intractable problems in ophthalmology is the maintenance of corneal transparency, an attribute unique among organized and relatively thick layers of tissue in the animal world. It must be admitted that this book does not answer the problem but it does give a fascinating picture of its complexity, of some of the major factors involved, of the lines of approach, present and past, by students in this field, and of the vast amount of work that has been done with the new techniques of phase-contrast and electron microscopy and of special staining, and in the field of biochemistry. In this symposium 22 authors have contributed papers under nineteen headings, each paper being followed by an interestingly argumentative discussion. The factors with which we are all familiar, the anatomical structure, metabolism, permeability, deturgescence, and the biochemical stability of the collagen-mucopolysaccharide complex are all important, but none in itself provides the complete answer; all these are interdependent and in this work they are fully discussed, together with such other factors as the physical properties and healing processes of the cornea, and the inductions and deductions which may be made from corneal vascularization, degenerations, and the results, good as well as bad, of clinical and experimental transplantation operations.

The ideal subject for a symposium is, very often, one that nobody knows much about. Many of us will be familiar with Macaulay's characteristic and caustic strictures of a work which he described as "deserving the praise, for what that phrase may be worth, of being the best book ever written by any man on the wrong side of a subject on which he was profoundly ignorant". Such a comment obviously applies to a monograph. The report of a good symposium such as this stands in sharp contradistinction. The dedicated search for truth, coupled with the frank admission of ignorance of basic essentials, is everywhere evident. The contributors to the discussion are warmly to be congratulated not only on their industry, but also on their frankness. They cannot fail to have profited from their interchange of views and their hours of discussion. Those of us who read this work will profit also in knowledge and in inspiration.

\section{NOTES}

Dr. J. Clement McCulloch has been appointed Professor of Ophthalmology and Head of the Department in the University of Toronto, succeeding Dr. A. J. Elliot who has joined the staff of the University of British Columbia.

\section{CORRIGENDA}

It is regretted that, in the article entitled "Experimental Hemeralopia uncomplicated by Xerophthalmia in Macacus rhesus" by F. C. Rodger, A. D. Grover, and A. Fazal, which appeared in the February issue (Brit. J. Ophthal., 1961, 45, 96), the blocks of Figs 3 and 4 (p. 103) have been transposed. Fig. 3 should be Monkey 7, deficient in vitamin A, and Fig. 4 should be the control.

Similarly, on p. 104, Fig. 5 should be Monkey 6, deficient in vitamin A, and Fig. 6 should be the control. 